\title{
A CULTURA POPULAR NA IDADE MODERNA: \\ QUESTÕES
}

\section{POPULAR CULTURE IN THE MODERN AGE: QUESTIONS}

Telma Piacentini*

Resumo: Caracterizar a cultura popular na Idade Moderna, na Idade Média e no Renascimento em torno de contextos culturais e históricos e da arte de Peter Bruegel nos possibilita entrecruzar segmentos significativos de nossa cultura contemporânea: os que teorizam e os que fazem, além de esclarecer questões normalmente ofuscadas para o público, o chamado leigo. $\mathrm{O}$ resultado pode revelar a erudição que o popular contém e, ao mesmo tempo, os mecanismos de luta entre o erudito e o popular, no interior da sociedade de classes. Dessa forma, torna-se possível nos reportar às lutas ao longo dos séculos e acumular conhecimentos para uma "leitura" e "interpretação" dos tempos atuais. Os embates e os constantes ataques que o popular enfrenta provocam modificações e perdas significativas para o público, precisamente, coletivo, permitindo-nos subliminarmente questionar "modelos" de democracia, em que quem perde é a maioria.

Palavras-chave: Idade moderna. Cultura popular. Transformações sociais. 
Abstract: Characterizing popular culture in the Modern Age, the Middle Ages and the Renaissance in terms of cultural and historic contexts and the art of Peter Bruegel allows us to interconnect significant segments of our contemporary culture: those which theorize and those which produce. It also allows clarifying issues that are normally obfuscated to the so-called lay public. The result can reveal the erudition that the popular contains and at the same time the mechanisms of struggle between the erudite and the popular within class society. This allows us to analyze the struggles over the centuries and accumulate knowledge for a "reading" and "reinterpretation" of current times. The conflicts and constant attacks faced by popular culture provoke significant modifications and losses for the public, precisely, the collective, allowing us to subliminally question "models" of democracy, where the majority loses.

Keywords: Modern age. Popular culture. Social transformations. 
Marcilio Ficino escreveu ao filho de Poggio Bracciolin: "A história é necessária, não apenas para tornar a vida agradável, mas também para lhe dar uma significação moral. O que é mortal em si mesmo consegue a ortalidade através da história; o que é ausente, torna-se presente; velhas coisas rejuvenescem; e um jovem logo iguala a maturidade dos velhos. Se um homem de setentas anos é considerado sábio devido à sua experiência, quão mais sábio aquele cuja vida abrange o espaço de mil anos! Pois, na verdade, pode-se dizer que um homem viveu tantos milênios quantos os abarcados pelo alcance de seu conhecimento de história." ("Carta a Giacomo Bracciolini", Marsilii Ficini. Opera omnia, Leyden, 1676, I, p. 658).

O conceito de "moderno" vem sendo empregado desde o século XII, na Europa Ocidental. Mesmo que de uma forma mais ou menos contínua, o significado do termo varia nos diferentes séculos. Assim, apesar de ser um vocábulo criado no período medieval (modernus) para designar os contemporâneos afetos às novidades em oposição aos que se apresentavam como defensores da sabedoria dos antigos, tinha um caráter depreciativo nos debates filosóficos de então. Os "moderni", na expressão de um desses defensores, eram "anões sobre os ombros de gigantes", os gigantes da Antiguidade.

Ao longo do Renascimento, os humanistas definiram a si mesmos por contraste ao que eles foram os primeiros a chamar de "Idade Média", um período visto como um tipo de "sala de espera" entre as glórias da Antiguidade clássica e a era do Renascimento em que supunham viver. Contudo, foi-lhes difícil decidir se o emprego do termo "moderno" referia-se aos seus predecessores medievais ou a si próprios. Alguns optaram pelo primeiro, outros pelo segundo.

No século XVII, o problema da equivalência ou primazia dos feitos quinhentistas em relação aos do mundo antigo tornou-se 
uma controvérsia de peso entre os intelectuais na França, Inglaterra e demais países, e a palavra "moderno" passou a designar um dos lados nesta "batalha dos livros". Foi nesta época que o adjetivo "novo" ganhou fama de termo respeitável, como no caso da "Nova Astronomia", de Kepler, e do "Discurso a Respeito de Duas Novas Ciências", de Galileu.

Os problemas persistiam. O crítico literário francês Jean Chapelain viu-se forçado a usar a fórmula contraditória "antiguidade moderna” para descrever a Idade Média, já que esse período, embora remoto, não era clássico.

Somente nos finais do século XVIII a "modernidade" ampliou seu significado e tornou-se o que Habermas denomina "um projeto", uma vez que o futuro parecia cada mais maleável e capaz de ser planejado. Cresceu a confiança na possibilidade de melhorar a condição humana por meio da ação política. A proclamação do "Ano Um" durante a Revolução Francesa foi uma cisão simbólica com o passado que teve como saldo ver os antigos modernos como parte de um "Ancien Régime".

No século XIX, as tecnologias, o conhecimento, as instituições sociais e mesmo as formas de arte podiam ser criticadas como "antiquadas", depreendendo-se daí que o aperfeiçoamento era infinito e o progresso inevitável, de modo que o correto e o desejável em certo momento talvez não o fosse no futuro. Foi essa modernidade própria ao século XIX, a modernidade da era do capitalismo industrial, das ferrovias e da Grande Exposição de 1851, que foi posta em tela de juízo por críticos culturais como Toqueville, Jacob Burckhardt e Dostoiévski, para quem a ideia do "Palácio de Cristal" era o símbolo de um Iluminismo superficial.

Da perspectiva histórica, a atual crise cultural (modernidade versus pós-modernidade) aparenta ser a última de uma longa sé- 
rie de ocorrências similares. Os participantes sempre julgam seu próprio movimento como o derradeiro, o "fim da história". Eles padecem de uma certa espécie de egocentrismo a que proponho dar o nome de "seculocentrismo".

Todos nos inclinamos a pensar que a era na qual vivemos é especial e a superestimar suas peculiaridades, seus problemas, seus encargos. Ao agir assim, pilhamo-nos em plena construção de um "outro" esteriotipado, em contraste a quem definimos a nós mesmos.

Autores conscientes de sua pós-modernidade tendem a formar uma imagem estereotipada do modernismo, do mesmo modo que os modernistas pelo mundo afora formam uma imagem estereotipada da sociedade tradicional.

No século XVIII, os que se proclamavam "esclarecidos" adotavam o estereótipo do "antigo regime" ou do "feudalismo", ao passo que os humanistas e reformadores do século XVI faziam uso de imagens igualmente "bárbaras" e "supersticiosas" da Idade Média. Era imprescindível que mitologizassem o passado para assim definir suas identidades. Mas, o preço desse estereótipo é alto, uma vez que ele representa um obstáculo à autoconsciência coletiva (Burke, 1989).

\section{Questões pontuais: a vitória da Quaresma e a provável reforma da cultura popular}

O quadro de Peter Bruegel, de 1559, O Combate do Carnaval e da Quaresma ou A Luta entre Carnaval e Lent, é ponto de partida para se entender as transformações que ocorreram na cultura popular a partir da Idade Média. O quadro trata da luta entre protes- 
tantes e católicos, representados, os primeiros, pelo príncipe Carnaval, gordo e alegre e os católicos pela Quaresma, magra e triste. O combate entre "um gordo escarranchado num barril" e "uma velha magra sentada numa cadeira" (BURKE, 1989, p. 231) pode ser entendido no contexto da Idade Média, em que indícios mostram que esta cena não era fruto da imaginação de Bruegel ou de outros pintores que a representaram, como Bosch, por exemplo, mas que era encenada em público. O Carnaval, geralmente, era uma homem gordo, alegre, jovial, barrigudo, colorido, às vezes enfeitado com comidas, como salsichas, aves, coelhos ou acompanhado de um caldeirão de macarrão (em Veneza, 1572) e a Quaresma, era uma velhinha triste, magra, vestida de preto e enfeitada com peixes: é curioso observar que o "Zé Quaresma” (Jack aLent) parece ser uma exceção como personagem masculino e que os palhaços famosos eram figuras carnavalescas pelos nomes que possuíam, como o "João Salsicha" (Hans Wurst) ou o "Arenque Azedo" ou “Estevão Bacalhau”, descarnados personagens da Quaresma. Em Bolonha, em 1506, foi encenado publicamente, um torneio entre o Carnaval, montado num cavalo gordo, e a Quaresma, num cavalo magro, seguidos, cada um, por um batalhão de simpatizantes.

O último ato da festa geralmente era uma cena em que o Carnaval enfrentava um processo simulado, fazia uma confissão e imitação de um testamento, era executado de brincadeira, em geral na fogueira e recebia um funeral de gozação. Ou, como acontecia em Veneza, um porco podia ser decapitado, numa alusão ao Carnaval, ou como em Madri, uma sardinha podia ser enterrada com todos as honras, aludindo-se à Quaresma (BURKE, 1989, p. 209).

Para estudiosos das Artes, como Rose-Marie e Rainer Hager (1995), o quadro pode ter a seguinte interpretação: 
Um bobo caminha [...] no centro do quadro O Combate do Carnaval e da Quaresma (1559, p. 51). Ilumina com um facho aceso um casal de adultos, apesar da claridade do dia, sinal dos mundos às avessas'. Pode estar às avessas em resultado dos duros combates travados entre católicos e protestantes, os primeiros representados por magras figuras de Quaresma e os segundos como glutões ávidos de prazer. À sua volta, Bruegel desenrola uma infinidade de cenas folclóricas: crianças a brincar, doentes que mendigam, vendedores de peixe, fiéis que saem da igreja com suas cadeiras, personagens mascarados, lembrando uma procissão. (HAGER, 1995, p. 51).

A figura do louco, que caminha ao centro da composição, mostra que a intenção de Bruegel não era apenas descrever a vida da comunidade ou os divertimentos de Carnaval. Alguns exegetas concluem a partir de quadros como este que Bruegel teria sido em primeiro lugar um "moralista popular": "Em cada uma de suas obras, procuram a mensagem didáctica, tratando cada quadro como uma obra de moralização." (HAGER, 1995, p. 50).

Não é somente o significado literal do quadro que é evidente, uma vez que as batalhas faziam parte das festas de entrudo, festas que chegaram aos nossos dias como brincadeira de carnaval. Outros significados têm gerado um grande debate, como o sentido apresentado pelo historiador Peter Burke. Na sua interpretação, o Carnaval, representado ao lado da taverna, simboliza a cultura popular tradicional e a Quaresma, que figura ao lado da igreja, como o clero, estava naquela época (1559) tentando reformar ou suprimir muitas festas populares.

Burke atribui a essa reforma a "tentativa sistemática” por parte de algumas pessoas cultas (que ele chama de "reformadores" ou de "devotos") de modificar as atitudes e os valores do restante da 
população. Não considera, porém, que os artesãos e os camponeses tenham sido "receptáculos passivos" da reforma; existiu um autoaperfeiçamento, conduzido também por artesãos devotos, como os "pregadores artífices" na Inglaterra do século XVII. Mas, o movimento da reforma foi liderado pelos cultos e entre esses, particularmente, o clero (BURKE, 1989, p. 230).

Essa investida contra a cultura popular na luta entre protestantes e católicos pode ser verificada por meio da tentativa constante de suprimir ou pelo menos purificar alguns itens da cultura popular tradicional. Mesmo que nem sempre era pelas mesmas razões ou pelas mesmas práticas tradicionais, os reformadores atacavam particularmente certas formas de religião popular,

[...] como as peças de milagres ou de mistérios, sermões populares e, acima de tudo, festas religiosas como os dias dos santos e peregrinação. Também se insurgiam contra inúmeros itens da cultura popular secular. Uma lista abrangente atingiria proporções enormes, e mesmo uma lista curta teria que incluir atores, baladas, açulamento de ursos, touradas, jogos de cartas, livretos populares, charivari, charlatães, danças, dados, adivinhações, feiras, contos folclóricos, leituras de sorte, magia, máscaras, menestréis, bonecos, tavernas e feitiçaria. (BURKE, 1989, p. 232).

O Carnaval é que concentra a maioria desses itens; é, pois, sobre ele que os reformadores investem conjuntamente. Mas não se restringem a ele: é um período de proibir e queimar livros, destruir imagens, fechar teatros, quebrar mastros de maio e dissolver "abadias de desgovernos".

Estamos na Idade Moderna, na Europa. A insistência dessas atitudes por parte dos reformadores protestantes e católicos parece estar concentrada em torno da separação entre o sagrado e o 
profano. Se na Idade Média esta separação já era motivo de conflito, no período que estudamos esta luta se agudizava para além de uma guerra entre devotos e não devotos: ela acompanha “[...] uma importante alteração na mentalidade ou sensibilidade religiosa. Os devotos se empenham em destruir a tradicional familiaridade com o sagrado, pois acreditavam que a familiaridade alimenta a irreverência." (BURKE, 1989, p. 235).

A perspectiva apresentada por Burke para a interpretação do quadro O Combate entre o Carnaval e a Quaresma, de Bruegel, permite estabelecer comparações e diferenças no ataque sistemático realizado pelos cristãos, protestantes e católicos, contra a cultura popular tradicional, durante os anos de 1500 e 1800. Burke afirma que, nesse movimento, os reformadores católicos e protestantes não tinham a mesma hostilidade em relação à cultura popular e, quando eram hostis, não era pelas mesmas razões. A reforma católica tendia a significar modificações e a reforma protestante era mais inclinada a eliminações. Seus estudos permitem concluir que “[...] os religiosos parecem ter condenado a cultura popular em termos muito parecidos desde os primeiros dias do cristianismo em diante. Essa tradição de condenação sugere que a cultura popular é notavelmente resistente." (BURKE, 1989, p. 241).

Para podermos visualizar como esse movimento agiu, utilizaremos uma artimanha didática, recurso que permite separar para simplificar e, posteriormente, reunir para o resgate de ideias que possam configurar a complexidade das ações desencadeadas nesse período.

Comecemos com os argumentos pela reforma tipicamente protestante, destacando os que tiveram maior peso nesse "combate": 
- a ideia de que as festas eram resquícios de papismo, acrescida da denúncia de que muitos costumes populares eram reminiscências pagãs. Consequentemente, queriam abolir tanto os feriados como as festividades e, alguns, se opunham tanto à Quaresma como ao Carnaval.

- a oposição a todos os dias santos além dos domingos e a oposição à própria ideia de festa tem embutida a não aceitação de que alguns dias são mais sagrados do que outros.

- a crítica às imagens sagradas, consideradas ídolos que deviam ser eliminados: tanto as "cerimônias" como os "ídolos" eram atacados como formas de religião exterior que se interpunham entre Deus e o homem e tinham, portanto, que ser abolidos.

- as duas principais objeções religiosas estavam centradas no Carnaval: a primeira, pelo seu caráter "não cristão" e a segunda porque, nessa ocasião, "o povo se entregava à licenciosidade".

- reprovavam muitos costumes populares acusando-as de reminiscências pagãs, "superstições" no sentido original do termo. O fato de muitos reformadores serem instruídos nos clássicos, permitia que fizessem comparações entre as festas antigas e as modernas: comparavam o Carnaval moderno às bacanais dos tempos antigos;

- também se referiam à celebração da véspera de Reis como uma renovação do paganismo, à invocação de Febo tirando-se sortes e augúrios em "feijões";

- os jogos de maio ingleses eram comparados à antiga festa de Flora;

- os costumes pagãos eram considerados diabólicos, como seus deuses e deusas;

- o culto à Virgem Maria era comparado ao culto de Vênus; 
- os santos eram descritos como sucessores dos deuses e heróis pagãos, que tinham assumido suas funções de curar doenças e proteger dos perigos;

- São Jorge era identificado como um novo Perseu e São Cristóvão, como um segundo Polifemo;

- comparavam a Roma cristã e a Roma pagã e denunciavam as semelhanças;

- denunciavam a magia como uma sobrevivência pagã: Circe e Medeia eram feiticeiras?

Com estes argumentos acusavam os católicos de praticar uma religião mágica, levando-os a um contraataque que, em última instância, concentrou-se em torno da cultura popular para expurgar os chamados "sortilégios e fórmulas mágicas" e apresentarem-se como a verdadeira religião cristã.

A reforma católica significou a tentativa de modificações do contexto popular. Basicamente, agiam da seguinte forma:

- insistiam que alguns dias eram mais sagrados que outros, mas essa insistência levou-os a atacar a profanação do tempo festivo, que era um tempo sagrado, com atividades mundanas;

- preocupavam-se com a tendência do Carnaval estender-se até a Quaresma; argumentavam que seria impossível alguém guardar a Quaresma com devoção adequada se tivesse se entregue ao Carnaval imediatamente antes;

- denunciavam a tradição de dançar e encenar peças nas igrejas e mesmo no quadro, pois uma igreja é um local sagrado;

- proibiam que os leigos se vestissem de padres durante a época de Carnaval; era considerado blasfêmia, pois os clérigos eram pessoas sagradas; 
- proibiam o clero de participar das festas populares à maneira tradicional, dançando e usando máscaras como os outros; também foram proibidos de assistir peças, comparecer a touradas e de gesticular "com excessiva violência durante os sermões", pois o seu status sagrado exigia gravidade e decoro;

- não atacavam o culto aos santos, mas aos seus "excessos", a crença em certas estórias ou a esperança de favores mundanos, como curas e proteções. Defendiam a imagens, embora fossem contra alguns exemplos específicos, como aconteceu com São Jorge: um livreto sobre a vida deste santo, publicado em Augsburg, em 1621, conta a história de sua vida e martírio, mas não faz nenhuma referência ao dragão, possivelmente rejeitado como apócrifo. Na Idade Média eram comuns as encenações ao vivo os quadros vivos - no dia de São Jorge; representavam, também, Santa Margarida e o dragão. Em 1552, os santos foram abolidos porque "cheiravam a papismo" e o dragão sobreviveu até 1835. Assim, a reforma da cultura popular na Augsburg católica significou mostrar São Jorge sem o dragão e na Norwich protestante mostrar o dragão sem São Jorge;

- as modificações eram introduzidas de forma planejada e realizadas sistematicamente: já em 601 d.C., o papa Gregório, o Grande, aconselhava ao bispo Agostinho que “[...] os templos dos ídolos não devem ser destruídos em hipótese alguma; os ídolos devem ser destruídos e os templos convertidos em igrejas, e como eles tem o costume de sacrificar muitos bois a demônios, deixe que alguma outra solenidade o substitua em seu lugar." (BURKE, 1989 , p. 252). Burke continua demonstrando que o princípio básico de Gregório era que “[...] é certamente impossível erradicar todos os erros de mentes obstinadas de um só golpe, e quem quer 
escalar uma montanha até o alto sobe gradualmente passo a passo e não de um só salto.” (BURKE, 1989, p. 252); essa doutrina de "adaptação" pode explicar como uma festa pagã de Solstício de Inverno pôde sobreviver como Natal e uma festa de Solstício de Verão, sobreviveu como o nascimento de São João Batista, a nossa festa junina de São João e como ainda no século XVII o clero era aconselhado, na França de Luís XIV, sobre que atitude deveria assumir em relação às fogueiras da noite de São João.

Mas, nem sempre os católicos e os protestantes estiveram em lados opostos nesse movimento de reforma da cultura popular. Juntos, apesar de manterem características próprias:

- atacavam o teatro como magia perigosa e as bruxas não porque fizerem mal, mas porque eram hereges adeptas de uma falsa religião, adoradoras de deusas pagãs, como Diana e outras;

- juntos, denunciavam os rituais populares como irreverentes, blasfemos, escandalosos, ofensivos a olhos e ouvidos piedosos, profanadores dos mistérios sagrados e escarnecedores da religião. Os devotos, tanto católicos quanto protestantes, viam o costume tradicional de eleger bispos-meninos ou abades dos tolos como uma zombaria à hierarquia eclesiástica e o sermão do bispo-menino, momento alto da festa tradicional, era considerado "uma ridicularização e não glorificação de Deus ou honra de seus santos”; o charivari também era visto como um escárnio ao sacramento do matrimônio e os ritos de iniciação, como dos oficiais chapeleiros, alfaiates e outros artesãos de Paris, que incluíam uma espécie de missa e derramar água sobre a cabeça do iniciante foram condenados em 1655 por uma comissão de doutores em teologia, que consideraram uma "profanação do batismo sagrado e da santa missa"; 
- juntos, atacavam também o sermão popular. Argumentos como "os pregadores contam estórias ridículas e contos de velhas à maneira de bufões e fazem a congregação rir às gargalhadas", ou "não é adequado, conveniente ou louvável que os homens promovam ocasião de risos nos sermões" ou, ainda, as reprovações aos pregadores que "faziam os ouvintes rir ou chorar", que "inseriam estórias fabulosas em seus sermões", que usavam "expressões coloquiais" que podiam ser usadas num bordel, que "faziam comparações ridículas ou blasfemas, como aquela entre o Paraíso e uma estalagem espanhola";

- juntos, também atacavam a peça religiosa popular como oportunidade de inconvenientes e exageros, como as peças sobre a Paixão de Nosso Senhor Jesus Cristo ou sua Ressurreição ou o Natal. Contra o teatro profissional, a acusação era a de que atores de maus princípios representassem a vida dos santos. $\mathrm{E}$ as procissões religiosas eram condenadas se incluíssem animais ou crianças nuas, representando anjos: os animais foram considerados apócrifos, como o dragão de São Jorge e o porco de Santo Antonio de Antão, que teve sua imagem enterrada, porque um animal não combinava com a imagem sagrada de um santo;

- e, juntos, atacavam a falta de moral da cultura popular tradicional: as festas eram denunciadas como ocasiões de pecado, principalmente pela embriagues, pela imoralidade da dança, por serem ocasiões de violência e por constituírem "vaidades", desagradando a Deus por desperdício de tempo e de dinheiro.

Como consequência a esses ataques frontais e sistemáticos, tanto os protestantes quanto os católicos começaram a criar uma 
cultura substitutiva e, nesse período, duas éticas ou duas concepções de vida rivais, conviveram em conflito aberto. A ética dos reformadores foi construída em torno de princípios tais como "decência, gravidade, modéstia, ordem, prudência, razão, autocontrole, sobriedade e frugalidade", componentes que mais tarde são identificados como uma típica "ética pequeno-burguesa", a ética dos comerciantes. $\mathrm{O}$ conflito dava-se com uma ética tradicional mais difícil de se definir, pois tinha uma menor “[...] clareza de expressão, mas que envolvia uma ênfase maior nos valores da generosidade e da espontaneidade e uma maior tolerância em relação à desordem." (BURKE, 1989, p. 237).

Vale lembrar as duas concepções de vida já identificadas na Idade Média como convivendo em torno de uma espécie de entrecruzamento, a que deriva da cultura cômica popular e a outra, marcada por traços burgueses, expressando um modo de vida preestabelecido e fragmentário. Podemos identificar esses traços numa ética fortalecida nesse período de 1500-1800, como a ética dos comerciantes, a vencedora nesse combate.

É de se salientar que a reforma da cultura popular deu-se tanto na Europa Ocidental quanto na Europa Oriental, a despeito das diferenças de credo religioso. Vale registrar que os teatros foram fechados, na Europa Ocidental, no século XVII, tanto na Madrid católica como na Londres protestante. E que na Igreja ortodoxa russa, em 1551, um famoso concílio chamado "cem leis" denunciou os jogos de "origem grega e invenção diabólica" que eram realizados na noite de São João e durante o Natal.

Se as reformas medievais foram essencialmente esforços esporádicos realizados a nível individual, como podemos verificar em documentos da Inquisição e a natureza desses esforços estava con- 
dicionada a natureza das comunicações, tanto em nível de estradas quanto de livros, o mesmo não se pode dizer do período moderno, depois do Concílio de Trento, que realizou suas últimas e decisivas sessões em 1562 e 1563: para se contrapor à Reforma protestante, os bispos católicos reunidos em Trento lançaram vários decretos para a reforma da cultura popular. Vários sínodos e concílios foram realizados na Europa católica e a novidade a partir dos anos de 1560 em diante foi a preocupação com a mudança das festas e as crenças do "povo inculto". O movimento a partir daí, organizado dentro da Igreja católica, fortaleceu os reformadores individuais. E a consequência, somada às investidas dos protestantes, foi o fechamento de teatros, a proibição de peças de mistério e de livros teológicos, mas também de baladas e de livretos populares.

Apesar da resistência de alguns clérigos e da resistência coletiva de leigos que respondiam às investidas dos reformadores com brincadeiras "politizadas", isto é, atacando às proibições com atos irreverentes durante as festas populares, como a queima da vecchia, a imagem da Quaresma ou as sátiras ridicularizando as mudanças impostas, nesses combates entre o Carnaval e a Quaresma, os devotos é que diziam as últimas palavras. E constatamos que entre 1550 e 1560 muitos costumes tradicionais foram abolidos, como também a metade do século XVII pode ser apontada como o término da primeira fase da reforma da cultura popular, reforma conduzida pelo clero, protestante e católico, em torno de questões teológicas. A segunda fase foi realizada mais por iniciativa dos leigos e atingiu, principalmente, uma "reforma dentro da reforma”.

Estes argumentos são suficientes para percebermos que a tentativa sistemática da parte da elite, primeiro do clero ca- 
tólico e protestante e, depois, dos movimentos leigos de renovação religiosa, conseguiram reformar a cultura do povo comum: a resistência da cultura popular começou a ceder e ocorreram importantes transformações, mas até onde e com que rapidez essas transformações se deram, e como o povo apropriou-se das novas formas de cultura protestante e católica, são questões difíceis de se responder.

Mesmo que, em volta de 1650, ocorreram importantes transformações na Europa protestante e nas regiões mais urbanizadas, em grande parte da Europa católica e nas regiões de difícil acesso, a sobrevivência do catolicismo "pré-Reforma" estendeu-se, ainda, por muito tempo. Basta lembrar que em 1740, nas terras de Languedoc, praticamente um século depois do ataque constante e forte de dois bispos reformadores enérgicos que proibiam danças em dias de festas, adivinhos, atores ambulantes e o que chamavam ignorância generalizada sobre religião, os devotos ainda viviam esse tipo de problema: o pároco de um lugarejo de Languedoc, que negava os sacramentos a pessoas que participassem de danças, foi objeto de um ritual simulado, quando um bando de mascarados carregou um boneco vestido de padre, antes de espancá-lo e queimá-lo.

A batalha entre o Carnaval e a Quaresma ainda prosseguia (Burke, 1989, p. 257-259). Também nas áreas protestantes, apesar de modo menos expressivo, se encontram exemplos de resistência da cultura popular, como na Noruega que, no século XVIII, ainda sobreviviam crenças católicas e mesmo pagãs; também nas Terras Altas da Escócia, os pastores que se colocavam contra as canções e baladas tradicionais também tiveram que lutar até o século XVIII e em torno de 1700 ainda foram encontradas muitos costumes católicos e pré-cristãos nas ilhas ocidentais escocesas (Burke, 1989, p. 260-261). Mas a 
batalha entre o Carnaval e a Quaresma já não é a mesma. A divisão entre católicos e protestantes toma outra feição: agora, a luta é patrocinada pela ação crescente dos leigos, provocando uma reforma dentro da reforma. Os movimentos de renovação religiosa, tanto os jansenista entre os católicos quanto os "pietistas" entre os protestantes, se encarregavam não só de queimar as rabecas e pregar contra canções, contos e danças folclóricas, como tomar providências contra feiras, apostas, mascaradas, peças, tavernas, prostitutas, como também “[...] diziam aos seus ouvintes que refletissem por si mesmo sobre a religião, ao invés de apenas ouvir o clero." (Burke, 1989, p. 261-264).

A partir daí as reformas tomaram rumos incalculáveis. Uma diferença notável refere-se ao sobrenatural: os primeiros reformadores da cultura popular acreditavam na eficácia da magia e insurgiram-se contra ela, denunciando como diabólica; insere-se aí as grandes caças às bruxas que tiveram seu ponto alto no final do século XVI e início do século XVII. Os reformadores da segunda fase não levavam a feitiçaria mais a sério; em algumas dioceses, nos séculos seguintes, eram os religiosos que subiam as montanhas para impedir que o povo local queimasse as mulheres suspeitas de bruxarias e foi um pastor calvinista que escreveu um livro para provar que a crença em bruxas era uma tolice. No final do século XVII os magistrados não levaram mais a sério a feitiçaria, na Inglaterra e na França; nas pequenas cidades do sudoeste da Alemanha o declínio se deu porque os magistrados não se julgaram mais capazes de identificar as bruxas, e na Polônia, este declínio deu-se somente no século seguinte.

Mesmo assim, não se pode afirmar que houve um "declínio da magia" em nível popular antes de 1800: a chamada "gente astuta" 
parece ter se mantido ativa no século XIX e mesmo no início do século XX, em muitas partes dessa mesma Europa, sobrevivendo ao ceticismo das classes superiores como sobreviveram aos caçadores de bruxas. Mas se pode afirmar que muitas expressões da cultura popular ultrapassaram os limites do século XVIII: encontramos peças de mistério, baladas de rua, touradas e farras de bois, teatro, cantores de rua, dia dos tolos ou da mentira, magias, receitas populares etc.

Pode-se dizer que os reformadores alcançaram mais do que pretendiam, uma vez que o movimento teve consequências para além do previsto. A mais importante dessas consequências foi o aumento da separação entre a grande e a pequena tradição. Os reformadores não pretendiam criar uma cultura própria, expurgada e separada: queriam atingir o povo, trazer todos para o seu lado. $\mathrm{Na}$ prática, as coisas aconteceram diferente: afetaram mais rápida e profundamente a minoria culta do que as outras pessoas e aprofundaram a separação dessa minoria em relação às tradições populares (Burke, 1989, p. 265).

É de se destacar, finalmente, que as transformações ocorrem por condições objetivas e não só porque alguém ou alguns querem. Isto quer dizer que as transformações que ocorreram entre 1500 e 1800 na cultura popular europeia tomaram rumos que nenhum contemporâneo poderia prever. Na verdade, podiam apenas ter uma ideia parcial ou vaga do que estavam pretendendo e do que estava acontecendo. É, porém, o cenário das grandes transformações econômicas, sociais e políticas do período o grande artífice das transformações ou reformas da cultura popular. A cultura popular está intimamente relacionada com o seu ambiente, adaptada a diferentes grupos profissionais e modos de vida regionais. $\grave{A}$ 
medida que o ambiente muda, a cultura acompanha essas transformações (Burke, 1989, p. 272).

Podem ser apontadas como mudanças que interferiram diretamente na transformação cultural no período moderno: o crescimento populacional e a ascensão das cidades; as transformações econômicas, como a "revolução comercial" da época ou "o crescimento do capitalismo comercial"; a iniciante empresa industrial; a revolução nas comunicações; a relação entre preço e salários; enfim, um processo complexo em que a revolução comercial levou a uma idade de ouro na cultura popular tradicional - pelo menos na cultura material, e nas cidades maiores - antes que as revoluções comercial e industrial, juntas, a destruíssem.

Se fizermos uma exemplificação retroativa ao início dos ataques às recreações populares, tomando como referência os anos de 1500, podemos demarcar alguns tópicos importantes: nesse período, é denunciado o costume de encenar as festas de Natal, as festas dos Bobos e as vigílias nas igrejas: "Eles fazem vigílias, mas são perversas e desavergonhadas. Alguns dançam nas próprias igrejas e cantam cantigas obscenas, outros... jogam dados.” (Burke, 1989, p. 240). Recuando para o século XIII, encontramos as censuras aos cleros que organizavam "peças que chamam de milagres", e "outras peças que chamam de apresentação de Maio ou do Outono". No século XII tinham sido atacadas todas as peças religiosas. Esses ataques também são encontrados na Rússia, atingindo "precedentes bizantinos”, e assim podemos prosseguir, recuando até a época dos “[...] pais da Igreja, como Agostinho, que ficava chocado ao ver as pessoas vestidas com peles de animais no dia do Ano-Novo, e também Tertuliano, 
que criticou a participação cristã nos spectacula (espetáculos de gladiadores) e nas saturnalia.” (Burke, 1989, p. 240-241).

\section{Retornemos ao marco referencial: prováveis consequências}

Até 1500,

[...] a cultura era uma cultura de todos: uma segunda cultura para os instruídos e a única cultura para todos. Em 1800, porém, na maior parte da Europa, o clero, a nobreza, os comerciantes, os profissionais liberais - e as suas mulheres - haviam abandonado a cultura popular às classes baixas, das quais estavam agora mais do que nunca separados por profundas diferenças de concepção de mundo. (BURKE, 1989, p. 291).

Essas transformações causaram o aparecimento de novos tipos de heróis.

Ao lado dos tradicionais - santos, cavaleiros, governantes e fora da lei - apareceu o hussardo, uma nova forma de cavaleiro; o contrabandista, uma nova espécie de fora da lei; o empresário, um tipo inteiramente novo de herói. E Burke avança na tipificação destes heróis:

No século XVIII, eram correntes os livros de boas maneiras em forma de folhetos, e diziam ao leitor como escrever uma boa carta ou abordar o sexo oposto, com uma lista de elogios apropriados, como 'prezo mais o seu casto amor que todas as riquezas da Índia'. (BURKE, 1989, p. 279).

As classes superiores estavam se retirando da cultura popular, de uma forma decisiva e demonstrativa. Além da elaboração de 
um novo tipo de vida, configurada por novos códigos e valores, que lhes proporcionavam inclusive um outro "visual", os cultos começaram a selecionar, para si, uma outra língua. A separação, portanto, não poderia deixar de acontecer.

Mas, o que liam os modernos? Burke afirma que, se os historiados que lessem uma série de livretos publicados entre 1500-1800 ficariam impressionados com a presença esmagadora da tradição: os mesmos gêneros e os mesmos textos. Os mascates que eram presos pelos funcionários públicos nas estradas tinham a mesma literatura. Ainda em 1812 um mascate alemão tinha, entre seus 36 livros, uma obra sobre a interpretação de sonhos, a vida de Genoveva de Brabante, o romance dos quatro filhos de Aymon e os chistes de Till Eulenspiegel. E um mascate francês preso em 1825 tinha 25 livros, entre eles o livro de sonhos, os quatro filhos de Aymon, Pierre de Provença e o Gato de Botas.

Os almanaques, um dos tipos mais populares da literatura da época, pouco mudaram ao longo dos séculos e ofereciam os mesmos ensinamentos astrológicos, médicos, agrícolas e religiosos. Começa-se a pensar que a imprensa, ao invés de destruir, contribuiu para a conservação e difusão da cultura popular tradicional (Burke, 1989, p. 278-279).

A nova cultura estava impregnada de duas transformações graduais, mas relevantes: a secularização e a politização. A primeira, se referia não só a uma rejeição à religião e se concretizava em torno de uma descristianização (déchristianisation), mas também a configuração dos medos e esperanças em termos cada vez mais terrenos, o declínio do sobrenatural ou o que Max Weber chama de "desencantamento do mundo", fenômeno que marcará os séculos XIX e XX. 
Quanto à politização, acompanhada pelo desenvolvimento da imprensa e da alfabetização, mudou consideravelmente o cotidiano das camadas populares. Os episódio registrados por Burke apontam para um "enorme movimento", o da "educação do homem comum". Essa educação política foi "uma educação informal pelos acontecimentos" (Burke, 1989, p. 290). E o povo começou a conhecer e a discutir o que antes eram

[...] assuntos do Estado, não questões locais, mas as preocupações dos governantes, em outras palavras, a sucessão, a guerra, a tributação e os problemas econômicos e religiosos, na medida em que se impunham à atenção dos governantes. A consciência política poderia ser definida como o conhecimento desses problemas e suas possíveis soluções, envolvendo um 'opinião pública' e uma atitude crítica (ainda que não necessariamente hostil) em relação ao governo. (BURKE, 1989, p. 281).

É um período marcado por grandes transformações na cultura erudita - a era da Renascença da Reforma e Contrarreforma, da Revolução Científica e do Iluminismo (e cada uma desses termos é uma abreviatura de um movimento não só complexo, mas em contínua transformação). A cultura popular europeia esteve longe de ser estática durante esses três séculos, mas na verdade, não se transformou e, nem poderia, com tanta rapidez.

Para Burke, apesar da existência de todos os tipos de contatos entre a cultura erudita e a cultura popular, não foi suficiente para impedir que se aumentasse o fosso entre elas, pois as tradições orais e visuais não conseguiram absorver rápidas transformações, “[...] ou para mudar a metáfora, elas eram resistentes às transformações, acostumadas a tomar o novo e transformá-lo em algo muito semelhante ao antigo." (Burke, 1989, p. 301). 
Com a retirada das classes superiores e a ampliação gradativa do fosso entre as duas culturas, um novo personagem entra em cena: e vem sob a égide das classes superiores.

\begin{abstract}
'Algumas pessoas cultas começaram a encarar as canções, crenças e festas populares como exóticas, curiosas, fascinantes, dignas de coleta e registro'. O resultado dessas atitudes é uma grande 'descoberta' do popular. Se em 1500 os homens cultos 'desprezavam as pessoas comuns, mas partilhavam de sua cultura. Em 1800, seus descendentes tinham deixado de participar espontaneamente da cultura popular, mas estavam-na redescobrindo como algo exótico e, portanto, interessante'. (BURKE, 2005, p. 306).
\end{abstract}

Para finalizar, vale o registro de um dos momentos históricos do Combate entre o Carnaval e a Quaresma. Em 1794, no 14 de julho, em Paris, o Dia da Tomada da Bastilha foi comemorado de forma carnavalesca, com o cerco e a tomada de um castelo de imitação, cheio de espantalhos (Burke, 1989, p. 288).

Cabe, ainda, o registro de algumas formas de continuidade dessa luta, nos nossos dias: no último dia de Carnaval do ano de 1998 numa entrevista à televisão, o Arcebispo da Bahia declarava a necessidade de o Carnaval parar para respeitar a Quarta-Feira de Cinzas, início da Quaresma; um representante do Candomblé, de posto equivalente ao do Arcebispo, declarava que o Carnaval deveria continuar na quarta, na quinta, na sexta ou no domingo, "quando o povo achasse que deveria parar”. Isto é, na luta entre o carnaval e a quaresma, a presença das diferentes religiões, agora, comportam-se de maneira diferente, mas o embate continua.

E, recentemente, em pleno século XXI, na atividade cultural promovida pelo poder instituído em regime democrático, por in- 
termédio do voto da maioria, a imposição da censura estatal ao espetáculo popular e à falta de transparência na determinação das verbas públicas para o evento, ocasionaram uma grande manifestação de repúdio da classe dos artistas, grupos organizados, produtores culturais e público participante durante os episódios da $3^{\text {a }}$ Maratona Cultural da cidade de Florianópolis, no mês de março de 2013: mais uma vez o famoso embate agora entre cultura popular e poder constituído se faz presente na nossa sociedade, envolvendo ainda diversos setores, mas continuando uma luta secular que, em diferentes tipos de sociedade, mudando tempo e espaço, continuam a mesma luta, consubstanciada na prerrogativa do popular: resta-nos concordar com a pergunta de Farruco Sesto Novas: "O que é, em definitivo, uma revolução, senão o maior ato poético elaborado no coletivo?” (Moysés, 2013).

\section{Referências}

BAKTIN, Mikhail. A Cultura Popular na Idade Média e no Renascimento. Tradução Yara Frateschi Vieira. São Paulo: HUCITEC; Brasília: Editora da Universidade de Brasília, 1987.

BURKE, Peter. Cultura Popular na Idade Moderna. Tradução Denise Bottmann. São Paulo: Companhia das Letras, 1989.

AS máscaras seculares do 'moderno'. Folha de S.Paulo, São Paulo, 14 de julho de 1998. Especial Caderno Mais!

FICINI Marsilii. Opera omnia. In: PANOFSKI, Erwin. Significado nas Artes Visuais. Tradução J. Guinsburg. São Paulo: Perspectiva, 1974.

HAGUER, Rose-Marie e Reiner. Pieter Brueguel, o Velho, cerca de 1525 e 1569 e Camponeses, loucos e demônios. Tradução de Lucilia Felipe. Köln: Benedikit Thashen, Lisboa e Alemanha, 1995. 
MOYSÉS, Raquel. Que cesse o pranto... Fórum Cultural de Florianópolis, 21 mar. 2013. (mimeo.).

\section{Notas}

* Pesquisadora e professora aposentada da Universidade Federal de Santa Catarina, artista plástica e idealizadora do Museu do Brinquedo da Ilha de Santa Catarina (UFSC). Endereço para correspondência: Serv. Arvoredo, n. 149, CEP 88063-120. Telefone: (48) 3237-2284. E-mail: <telma.anita@gmail.com>. 